treatment for SD. No prognostic factors were found to correlate with PUK relapses and final visual acuity/ocular perforation.

Conclusions: Conclusions: RA and ANCA-vasculitis are the SD more frequently associated with PUK. Visual outcomes are poor in less than $50 \%$ of patients despite of topical and systemic GC/biologic therapy. SD-PUK may emerge previous to the SD diagnosis or with the associate SD in remission.

Disclosure of Interest: None declared

DOI: 10.1136/annrheumdis-2018-eular.4334

\section{AB0679 LEVEL OF SERUM 25(OH)D WITH DISEASE ACTIVITY OF A COHORT STUDY}

L. Hua. Department of Rheumatology and Immunology, Beijing Anzhen Hospital, Capital Medical University., Beijing, China

Background: Takayasu's arteritis (TAK) is a chronic large vessel vasculitis primarily involving the aorta and its major branches. TAK has been considered a rare disease that affected mostly young Asian women ${ }^{[1]}$. Its pathogenesis is still under investigation. However, some studies have demonstrated that immune disorder results in TAK. Especially cellular immunity plays a vital role in TAK. Recently, some studies shown that Vitamin D can regulate immune system in rheumatological diseases, such as SLE, RA and so on ${ }^{[2]}$. The relationship between Vitamin D and disease activity of TAK has not been reported yet. This study focuses on identifying the role of Vitamin $\mathrm{D}$ in pathogenesis of TAK through studying the correlation of serum 25(OH)D level and the disease activity of TAK

Objectives: To evaluate the level of serum 25-hydroxyvitamin D in patients with Takayasu's Arteritis (TAK)

Methods: Totally 57 untreated TA patients (TA group) and 51 healthy people (control group) were enrolled. The level of serum 25(OH)D were measured and compared between groups. The correlations of $25(\mathrm{OH}) \mathrm{D}$ level with related indicators were analysed.

Results: Lower concentrations of serum 25(OH)D were detected in TAK patients compared with healthy subjects $[(11.91 \pm 5.26) \mathrm{ng} / \mathrm{ml}$ versus $(17.64 \pm 8.85) \mathrm{ng} / \mathrm{ml}]$ $(p<0.01)$. In all patients with TAK, serum 25(OH)D correlated negatively with erythrocyte sedimentation rate (ESR), interleukin (IL) -6 $(r=-0.321, p=0.022$; $r=-$ $0.322, p=0.031)$. There was no correlation between serum $25(\mathrm{OH}) \mathrm{D}$ level and NIH score, ITAS2010 score, ITAS.A score, anti-tumour necrosis factor (TNF)-a antibody. TAK Patients with therapy showed a significantly higher serum level of $25(\mathrm{OH}) \mathrm{D}$ compared with that before therapy $[(10.74 \pm 3.49) \mathrm{ng} / \mathrm{ml}$ versus $(18.66$ $\pm 8.03) \mathrm{ng} / \mathrm{ml}](\mathrm{p}<0.01)$. After therapy, the changes of $25(\mathrm{OH}) \mathrm{D}$ level present a positive correlation with the changes of NIH score, ITAS2010 score AND ITAS.A score.

Conclusions: We observed a high prevalence of vitamin D deficiency in patients with TAK. The 25(OH)D levels in serum was negatively correlated with ESR and IL-6. Levels of $25(\mathrm{OH}) \mathrm{D}$ were improved after therapy. The changes of $250 \mathrm{HD}$ level correlation to Disease Activity of Index.

\section{REFERENCES:}

[1] Park S J, Kim H J, Park H, et al. Incidence, prevalence, mortality and causes of death in Takayasu Arteritis in Korea - A nationwide, populationbased study[J]. Int J Cardiol,2017,235:100-104.

[2] Altieri B, Muscogiuri G, Barrea L, et al. Does vitamin D play a role in autoimmune endocrine disorders? A proof of concept[J]. Rev Endocr Metab Disord,2017,18(3):335-346.

Disclosure of Interest: None declared

DOI: 10.1136/annrheumdis-2018-eular.5294

\section{AB0680 NON OPHTALMOLOGICAL NEUROLOGIC ISCHAEMIC MANIFESTATIONS OF GIANT CELL ARTERITIS}

L. Coronel Tarancón ${ }^{1}$, I. Monjo ${ }^{2}$, E. Fernández², A. Balsa², E. De Miguel ${ }^{2}$

${ }^{1}$ Hospital Universitario Nuestra Señora de la Candelaria, Santa Cruz de Tenerife;

${ }^{2}$ Hospital Universitario La Paz, Madrid, Spain

Background: Giant cell arteritis (GCA) is a very infrequent cause of stroke. It is diagnosed in $0.15 \%$ of brain infarctions. On the other hand, in scientifical literature there are very little patients with ischaemic brain infarctions that describes stroke as the clinical presentation of GCA. It might suggest that it is a underdiagnosed condition.

Objectives: To check the frequency of stroke as presentation symptom of GCA and other findings related with it.

Methods: Retrospective observational study of 123 consecutive patients diagnosed of GCA in our hospital. We reviewed the past medical history to obtain sings, symptoms and ultrasound parameters of the first medical evaluation. We searched for: age, sex, hypertension, diabetes, dyslipidemia, anterior ischaemic optic neuropathy (AION), headache, visual disturbances, Polymyalgia Rheumatica (PMR), jaw claudication, general symptoms, non oftalmological brain ischaemic symptoms, disease outbreak and laboratory test: erythrocyte sedimentation rate (ESR), $\mathrm{C}$ reactive protein (CRP), Haemoglobin $(\mathrm{Hb})$. For the analysis we divided the sample into two groups: a). Neurological symptomps b). Other presentations.

For statistical comparisons, we used SPSS version 17.0. Descriptive analysis and comparison was performed of the two groups. $\mathrm{X}^{2}$ was used for qualitative values and means comparisons for quantitative.

Abstract AB0680 - Table 1

\begin{tabular}{|c|c|c|c|}
\hline & $\begin{array}{l}\text { Non ophthalmic neurologic } \\
\text { symptoms }\end{array}$ & $\begin{array}{l}\text { Non neurologic } \\
\text { symptoms }\end{array}$ & $\begin{array}{c}\mathrm{p} \\
\text { value }\end{array}$ \\
\hline Age * & $79 \pm 5.42$ & $77,86 \pm 86$ & 0.62 \\
\hline Sex **(Women) & 7 (58,33\%) & $67(60,36 \%)$ & 0.56 \\
\hline $\mathrm{ESR}^{\star}(\mathrm{mm} / \mathrm{h})$ & $66,63 \pm 32.24$ & $68,18 \pm 30,41$ & 0.89 \\
\hline $\mathrm{CRP}^{\star}(\mathrm{mg} / \mathrm{L})$ & $53,73 \pm 79,43$ & $42,55 \pm 45,35$ & 0.60 \\
\hline $\mathrm{Hb}^{\star}(\mathrm{g} / \mathrm{dL})$ & $12,56 \pm 2.12$ & $13,34 \pm 4,71$ & 0.64 \\
\hline Outbreak $^{\star *}$ & $5(41,66 \%)$ & $57(51,35 \%)$ & 0.52 \\
\hline Headache ${ }^{\star \star}$ & $6(50 \%)$ & $68(61,26 \%)$ & 0.22 \\
\hline $\begin{array}{l}\text { Visual } \\
\text { disturbances }{ }^{\star *}\end{array}$ & $1(8.33 \%)$ & $24(21,62 \%)$ & 0.27 \\
\hline $\mathbf{P M R}^{\star \star}$ & $0(0 \%)$ & $25(22,52 \%)$ & 0.06 \\
\hline Jaw claudication ${ }^{\star *}$ & $0(0 \%)$ & $14(12,61 \%)$ & 0.19 \\
\hline $\begin{array}{l}\text { General } \\
\text { symptoms }^{\star \star}\end{array}$ & $1(8,33 \%)$ & $20(18,01 \%)$ & 0.61 \\
\hline Total patients & 12 & 111 & \\
\hline
\end{tabular}

${ }^{*}$ Mean \pm SD. ${ }^{* *} \mathrm{n}(\%)$.

Results: Of our 123 patient's cohort: 37 patients (30.08\%) suffered from ischaemic events of the internal carotid artery, 25 patients $(20.32 \%)$ of AION and 12 patients $(9.8 \%)$ presented with neurological symptoms different from AION.

Out of the 12 patients with non ocular ischaemic symtomps of the central nervous system: $5(44.66 \%)$ were diagnosed of transitory ischaemic accident (TIA), 4 $(33.33 \%)$ of stroke, $2(16.66 \%)$ of $\mathrm{VI}$ cranial nerve paresis, one the patients that presented with III and VI par paresis suffered also from TIA, at last, one patien presented ischaemic phenomena related with small-vessels vasculitis and one patient with dizziness due to cerebellum affectation.

Clinical and analytical data are presented in the table:

No patient was presented with PMR or jaw claudication.

$3(25 \%)$ patients died during the follow up in the neurologic symptoms group in comparison with $11(9.90 \%)$ of the non neurological ( $p 0.11)$.

Conclusions: Stroke is not a rare form of presentation of GCA and should be suspected in all ischaemic brain events that are associated with high acute phase reactants in elderly patients. It is important to identify these patients due to the severity of the disease and the possibility of specific treatment that may avoid new events.

\section{REFERENCES:}

[1] Roaa S. Alsolaimani, et al. Severe intracraneal involvement in Giant Cell Arteritis: 5 Cases and literature Review. J Rheumatol 2016; 43:3.

Disclosure of Interest: None declared

DOI: 10.1136/annrheumdis-2018-eular.5775

\section{AB0681 BIOPSY RESULTS FROM PATIENTS WITH SUSPECTED GRANULOMATOSIS WITH POLYANGIITISIN A DECADE (2005-2015). ALEATORISED SAMPLE ANALYSIS OF CLINICOPATHOLOGICAL CORRELATION}

L.F. Flores-Suarez $^{1}$, H. Echeagaray ${ }^{2}$, G. Tona-Acedo ${ }^{2}$, R.M. Rivera-Rosales ${ }^{3}$, N. Ruiz ${ }^{1}$, A. Castorena-Maldonado ${ }^{2} .{ }^{1}$ Primary Systemic Vasculitides Clinic; ${ }^{2}$ Department of Otorhinolaryngology, Head and Neck Surgery; ${ }^{3}$ Department of Pathology, Instituto Nacional de Enfermedades Respiratorias, Mexico City, Mexico

Background: The diagnostic yield of airway biopsies in granulomatosis with polyangiitis (GPA) is usually less than $50 \%$.

Objectives: To review the histologic diagnostic yield of airway biopsies sent with a suspected GPA diagnosis in a single-centre devoted to respiratory diseases by use of previously published criteria. Also, to know the interobserver variability among in-house pathologists, correlate signs and symptoms with GPA positive histologic findings, and with additional paraclinical data, apply the algorithm proposed by the European Medical Agencies (EMA) to know if a higher number of biopsies confidently supported a GPA diagnosis.

Methods: From 137 airways biopsies during a decade (2005-2015), fifty were randomly selected for the second review by an expert pathologist. Thereafter, with the incorporation of antineutrophil cytoplasm autoantibodies (ANCA) the EMA algorithm was applied. Demographic data were descriptively analysed, and 